\title{
Ameliorative effect of Albizzia procera leaves extract against experimentally induced gastric ulcer models in Wistar albino rats
}

\author{
Vivek Srivastava* \\ Amity Institute of Pharmacy, Amity University, Lucknow (Uttar Pradesh), India and Department of \\ Pharmaceutical Sciences, Motherhood University, Roorkee (Uttarakhand), India \\ Santosh Kumar Verma \\ Department of Pharmaceutical Sciences, Motherhood University, Roorkee (Uttarakhand), \\ India \\ Neha Mathur \\ Amity Institute of Pharmacy, Amity University, Lucknow (Uttar Pradesh), India \\ Kapil Kumar Goel \\ Department of Pharmaceutical Sciences, Gurukul Kangri University, Haridwar (Uttarakhand), \\ India \\ ${ }^{*}$ Corresponding author. Email: vsrivastava1@lko.amity.edu
}

\section{Article Info}

https://doi.org/10.31018/

jans.v13i1.2513

Received: January 20, 2021

Revised: March 6, 2021

Accepted: March 11, 2021

\section{How to Cite}

Srivastava, V. et al. (2021). Ameliorative effect of Albizzia procera leaves extract against experimentally induced gastric ulcer models in Wistar albino rats. Journal of Applied and Natural Science, 13(1): 308 - 315. https://doi.org/10.31018/ jans.v13i1.2513

\begin{abstract}
Albizzia procera belongs to family Fabaceae and has several phytoconstituents like flavonoids, terpenes, alkaloids, saponins etc. The plant is commonly used in traditional medicines. The objective of the present study was to assess the ameliorative effect of $A$. procera leaves extract against an experimentally induced gastric ulcer in albino rats. The antiulcer, antisecretory and cytoprotective properties of an ethanolic extract prepared from the leaves was evaluated. When given in a $200 \mathrm{mg} / \mathrm{kg}$ oral (per. os) dose, the extract produced $74 \%$ and $85 \%$ protection index in ethanol-induced ulcer model and pylorus ligation model, respectively. Additionally, the extract also prohibited the formation of haemorrhage and edema, significantly lessened catalase activity $(p<0.0001)$ and the lipid peroxidation level $(p<0.0001)$ in the glandular tissue of Wistar albino rats. Furthermore, the extract also significantly diminished the total acidity $(p<0.0001)$ of the gastric fluid by increasing its $\mathrm{pH}(\mathrm{p}<0.0001)$. The occupancy of different phytoconstituents in the extract, such as flavonoids and tannins were identified that may be responsible for its gastro -protective activity. All these results provide a basis explaining the antiulcer ability of $A$. procera being useful in the management of gastric ulcers.
\end{abstract}

Keywords: Antiulcer, Gastroprotective, Pylorus-ligation, Safed siris, Ulcer index

\section{INTRODUCTION}

Clinically, peptic ulcer can be defined as the most regular and familiar gastrointestinal disorder (Akhtar et al., 1992). These are the sore owing to the disparity between protective factors and damaging factors within gastroduodenal mucosa. Ulcer treatment is now primarily concentrated on reducing the harmful properties of invading secretion of acid, but novel search revived the development of safer medicine that can protect the gastric mucosa neither by disturbing acid secretion nor by deactivating intragastric acidity. Almost all the conventional drugs give rise to adverse effects like impotency, hematopoietic changes, gynecomastia and arrhythmias
(Ariypshi, 1986). On the other hand, plant extracts have exhibited some promising outcomes for managing gastric ulcers and are an interesting source for blooming new drugs (Pillai et al., 1978).

Albizzia procera belonging to family Fabaceae, commonly known as Safed Siris, naturally occurs in India, northern Australia, southern China, including Hainan and Taiwan. It has also been instigated into few African countries, along with Panama and Puerto Rico. The phytochemical examination of $A$. procera is reported for various secondary metabolites such as saponins, terpenes, alkaloids and flavanoids. Few bioactive compounds separated and recognized were new alkaloids (budmunchiamines A, B, C), triterpenoid saponins 
(julibroside), and two flavonol glycosides (quercitrin and/or isoquercitrin) (Sivakrishnan and Swamivelmanickam, 2019). The whole plant has utility in some way, such as leaves and pods are eatable portions, whereas its wood is a reasonable material for paper pulp. $A$. procera was stated to exhibit diverse pharmacological activities. The plant is used conventionally in convulsions, delirium, pain, and sepsis. The plant bark has spermicidal action (Azamthulla et al., 2015) and is also given for rheumatism and haemorrhage. A. procera exhibits several pharmacological activities, for instance, antimicrobial activity, Central Nervous System activity, cardiotonic activity, antioxidant property, anticancer etc. (Khatoon et al., 2014) (Kokila et al., 2013). The objective of the present study was to evaluate the antiulcer, antisecretory and cytoprotective properties of the leaves extract of $A$. procera in Wistar albino rats,

\section{MATERIALS AND METHODS}

\section{Plant material collection}

A. procera plant leaves were possessed from IndoGangetic plain regions of Lucknow, India. The herbarium was prepared and submitted for authentication to the National Botanical Research Institute (NBRI) Lucknow. The Authentication voucher specimen number is 97824.

\section{Ethanolic extracts preparation}

Fresh leaves of $A$. procera were collected, air-dried and powdered. Using a soxhlet extractor; $100 \mathrm{gm}$ of powdered drug was considered and extracted for $72 \mathrm{~h}$ taking $90 \%$ ethanol as a solvent. The extracted drug was concentrated in a water-bath at temperature $50-55^{\circ}$ $\mathrm{C}$ and dried in a desiccator (Kokate et al., 2015). Ethanolic extracts of $A$. procera leaves extracts (EEAP) were subjected to preliminary phytochemical analysis (Khandelwal, 2002).

\section{Determination of total phenolic, flavonoid content} and in vitro antioxidant property of extract

Leaf extract of $A$. procera was evaluated for total phenolic content (TPC) using Folin-Ciocalteau (FC) assay using Gallic acid standard curve. In the procedure, 0.5 $\mathrm{ml}$ of plant extracts were mixed with $1.5 \mathrm{ml}$ of Folin- C reagent diluted $1: 10 \mathrm{v} / \mathrm{v}$. Then after 5 minutes $1.5 \mathrm{ml}$ of $7 \%$ sodium carbonate solution was added. The final volume of the tubes was made upto $10 \mathrm{ml}$ with distilled water and allowed to stand for 90 minutes at room temperature. Absorbance of the sample was measured against the blank at $750 \mathrm{~nm}$ using Shimadzu UV-1600 Spectrophotometer and results were expressed in gallic acid equivalents (Ruchi and Rekha, 2017).

The total flavonoid content (TFC) of the leaf extract was determined by Aluminium chloride method using quercetin as the standard. $1 \mathrm{ml}$ of the test substance and 4 $\mathrm{ml}$ of water was added to a $10 \mathrm{ml}$ volumetric flask. Add $0.3 \mathrm{ml}$ of of $5 \%$ sodium nitrite, $0.3 \mathrm{ml}$ of $10 \%$ aluminium chloride was added after 5 minutes. After 6 minutes of incubation period at room temperature, $1 \mathrm{ml}$ of $1 \mathrm{M}$ sodium hydroxide was added to the reaction mixture. Immediately the final volume was made up to $10 \mathrm{ml}$ of distilled water. The absorbance of the sample was measured against the blank at $510 \mathrm{~nm}$ using Spectrophotometer and results was measured as milligram of quercetin present per gram of dried extract sample (mg QE/g) (Pekal and Pyrzynska, 2014).

The free radical scavenging activity of the extracts was determined by DPPH method. The $0.006 \% \mathrm{w} / \mathrm{v}$ of DPPH was prepared in $95 \%$ methanol. The ethanolic leaves extract was mixed with $95 \%$ methanol to prepare stock solution $1 \mathrm{mg} / \mathrm{ml}$. Freshly prepared DPPH solution was taken in test tubes and extracts were added by serial dilutions $(100-1000 \mu g)$ to every test tube. The final volume was $2 \mathrm{ml}$ and discolouration was measured at $517 \mathrm{~nm}$ after incubation for $30 \mathrm{~min}$ in dark using Spectrophotometer. Ascorbic acid was used as standard (Kedare et al.,2011).

\section{Experimental animals}

150-200g healthy Wistar albino rats were purchased from the Laboratory Animal Services Division of Central Drug Research Institute, Lucknow. During the study period, the International guidelines of the Organization for Economic Cooperation and Development for the humane treatment of the animals used in the study were followed. For keeping the animals, polyacrylic cages were used and all the standard housing conditions were sustained (room temperature $24-27^{\circ} \mathrm{C}$ ). This was accompanied by a $12 \mathrm{~h}$ light and dark cycle. Food and water were accessible ad lib. Food was not permitted between an hour before and till the conclusion of the behavioral studies. All the experimental procedures described and performed were studied and permitted through the Institutional Animal Ethics Committee (IAEC) and Committee for control and supervision of Experiments on Animals (CPCSEA), Amity Institute of Pharmacy. Amity University Uttar Pradesh, Lucknow.

\section{Treatment schedule}

Wistar rats of either sex (150-250 gram) were taken and grouped into 4 groups: each having 4 animals viz. Group 1: Positive Control ( $0.9 \%$ normal saline); Group 2: Negative Control (Ethanol induced and pylorus ligation induced); Group 3: Standard (Ranitidine $45 \mathrm{mg} / \mathrm{kg}$ ); and Group 4: EEAP (Ethanol $A$. procera leaves extract) (200 mg/kg). Two ulcer-inducing models, i.e., Ethanol induced ulcer model and Pylorus ligation induced ulcer model, were performed. Treatment was given orally for 14 days in all animals.

\section{Ethanol induced gastric ulcer model}


In this model, animals were administered orally with 1 $\mathrm{ml}(90 \% \mathrm{v} / \mathrm{v})$ ethanol to produce the gastric ulcers. The animals were fasted $24 \mathrm{~h}$ before the induction but had free access to water. Thirty minutes before treating with ethanol, different groups of animals were given $A$. procera leaves extract (test group), 0.9\% normal saline (negative control) and Ranitidine (standard group) orally and then sacrificed 30 minutes later the disease induction. The abdominal of the sacrificed animals was dissected out and the greater curvature of the stomach was observed for ulcer spots and hemorrhagic lesions. Ulcer score was then recorded accordingly. The length of each lesion was observed at $10 \times$ magnification and measured in $\mathrm{mm}$. Ulcer index per stomach was then totalized. Lastly, to learn the histopathological changes, all treated and ulcerated stomach were soaked in $10 \%$ formalin for $24 \mathrm{~h}$ (Kumar, et al.,2013; Misra et al., 2012).

\section{Method of ulcer rating}

Ulcerated stomachs were noticed for the wounds with the support of $10 \times$ lens and then rated 0 for the normal stomach, 0.5 for red pigmentation, 1.0 for 1-3 small lesions and ulcer spots, 2.0 for 3-5 lesions and hemorrhagic bands and 3.0 for more than 5 lesions.

\section{Calculation of ulcer index}

The average score of ulcers was calculated and stated as ulcer index for every individual group of animals. The extent of ulceration in the treated groups was equated to the Negative control groups in all the models.

Ulcer index $=(U N+$ US + UP $) \times 1 \backslash 10$

where.

..Eq. 1

$\mathrm{UN}=$ Average number of ulcer/animals

US $=$ Average severity score

$\mathrm{UP}=\%$ of animals with ulcers

$\%$ Ulcer inhibition= [Av. ulcer index for the Negative control group - Av. ulcer index for test group / Av. ulcer index for Negative control group] $\times 100$

\section{Histopathological evaluation}

All the dissected stomachs were dipped for $24 \mathrm{~h}$ in Formalin $(10 \%)$ to evaluate the possible modifications via Histopathological study. For tissue staining, Haematoxylin-eosin was used to review some transformations like gastric epithelium removal, infiltration of neutrophils, gastric erosions, inflammation and oedema (Brzozowski et al.,1998).

\section{Pyloric ligation induced gastric ulcer model}

The model involved the exposure of the animal's stomach under the light anesthesia ketamine $(40 \mathrm{mg} / \mathrm{kg})$. The experimental animals were kept on fasting for $24 \mathrm{~h}$ before the test was conducted with unrestricted access to water. The stomach was opened by making a small midline incision and the pylorus of the stomach was somewhat lifted out. Cautiously, the pylorus was replaced without affecting the blood supply after it was ligated. Lastly, the abdominal wall was sutured. Immediately following pyloric ligation, the animals were administered $0.9 \%$ normal saline (Group 2 : Negative Control), A. procera extract (Group 3: EEAP, Test Group) and Ranitidine (Group 4: Standard drug group, $45 \mathrm{mg} / \mathrm{kg}$ Body weight (bw) orally. Four hour after pyloric ligation the stomachs of the animals were dissected out after they were sacrificed with an excess of chloroform. All the gastric contents obtained from the dissected stomach were collected into graduated tubes. The contents were determined for their volume, total acidity, and $\mathrm{pH}$. Erosions were witnessed and then the glandular part of the stomach was cut open to expose the inner surface for the examination of ulcers and washed under a stream of water. Based on ulcers' diameter, all the erosions were counted and scored on a scale of 1 3. Ulcer index was enumerated as the total diameter of ulcers for each stomach divided by a factor 10 . Using the formula, the percentage of ulcer protection was calculated (Prabha et al.,2003).

\section{Biochemical estimations}

The collected gastric juice from the dissected stomachs was assessed for their volume and the $\mathrm{pH}$. It was then centrifuged and evaluated for different biochemical estimations (Srivastava et al.,2010).

\section{Determination of free and total acidity}

Topfer's reagent (2-3 drops) was added into a $100 \mathrm{ml}$ conical flask holding $1 \mathrm{ml}$ of gastric juice. Titration for the mixture was done using $0.01 \mathrm{~N}$ sodium hydroxide until the solution developed yellowish-orange. The amount of alkali added was observed, which corresponded to free acidity. For knowing the total acidity, the juice was again titrated by adding phenolphthalein solution (2-3 drops) and sustained up to the appearance of red colour. The total added amount of alkali was observed, which corresponded to total acidity.

\section{Calculation of acidity}

Acidity $=$ Volume of $\mathrm{NaOH}$ added $\times$ Normality of $\mathrm{NaOH}$ $\times 100 / 0.1(\mathrm{meq} / \mathrm{Lit} / 100 \mathrm{gm})$ ......Eq. 2

\section{Estimation of mucin}

The stomachs were everted following the assemblage of gastric juice and immersed for $2 \mathrm{~h}$ in $0.1 \%$ alcian blue $8 \mathrm{GX}$, which was prepared in buffered $0.16 \mathrm{M}$ sucrose with $0.05 \mathrm{M}$ sodium acetate whose $\mathrm{pH}$ was accustomed to $\mathrm{HCl}$. Through two consecutive washes with $0.25 \mathrm{M}$ sucrose solution at 15 and $45 \mathrm{~min}$, the formed uncomplexed dye was withdrawn whereas the complex formed between the dye and mucus was immersed in $0.5 \mathrm{M} \mathrm{MgCl}_{2}$ (magnesium chloride) $(10 \mathrm{ml}$ ). 
After $2 \mathrm{~h}$ of immersion, the developed blue solution with an equivalent volume of diethyl ether was agitated. Lastly, the aqueous phase was utilized for the determination of optical density using a Hitachi 1520 spectrophotometer at $605 \mathrm{~nm}$ (Saranya, et al.,2011).

\section{Estimation of catalase activity}

$0.4 \mathrm{ml}$ water, $1.0 \mathrm{ml}$ buffer and $0.2 \mathrm{ml}$ enzyme were measured and put into $0.5 \mathrm{ml}$ of the mixture (Reagent $A$ + Reagent B). $2.0 \mathrm{ml}$ acetic acid was added after incubating the complete mixture for $0,30,60,90$ seconds and then heated for 10 minutes. The colour established after heating was declaimed at $610 \mathrm{~nm}$. Catalase activity was calculated in moles of decomposed $\mathrm{H}_{2} \mathrm{O}_{2} / \mathrm{min} /$ mg protein (Aebi, 1984).

\section{Evaluation of lipid peroxidation (LPO)}

Sample $(1.0 \mathrm{ml})$ was possessed and put into $2.0 \mathrm{ml}$ TCA-TBA-HCL reagent. For 15 minutes, the mixture was heated in a steaming water bath. The heated solution was cooled and centrifuged at $1,000 \mathrm{~g}$ for 10 minutes. The flocculent precipitate was discarded, whereas clear supernatant was utilized. The readings were taken at $535 \mathrm{~nm}$ and LPO was stated as nmoles of formed MDA/min/mg protein (Buege et al.,1978).

\section{RESULTS AND DISCUSSION}

The total phenolic Content and total flavonoid content in each gram of extract of $A$. procera were found as milligram equivalent gallic acid $46.9 \mathrm{mg} \mathrm{GAE} / \mathrm{g}$ and $35.3 \mathrm{mg} \mathrm{QE} / \mathrm{g}$, respectively, suggesting its antioxidant activity which is vital for the cytoprotection and ulcer healing potential of Albizzia leaves' extracts. The DPPH scavenging activity of leaf extract was found to be $13.35 \mu \mathrm{g} / \mathrm{ml}$ (Fig. 1). The antioxidant effect of Albizzia was mainly due to the presence of phenolic components and flavones.

Oral administration of absolute $90 \%$ ethanol produced distinguishing lesion in rats of Negative control group, Standard group and EEAP group. The rat stomach's glandular portion showed normal architecture in positive control whereas Negative control showed redness, 8-10 red spots \& hemorrhagic streaks. Ranitidine group showed 1-2 red spots \& EEAP group showed 2-3 red spots (Fig 2). The ulcer index in Negative Control, Ranitidine (45mg/kg oral) and EEAP (200mg/kg per.os) was $9.25 \pm 0.15,1.11 \pm 0.18,1.85 \pm 0.15$ respectively. The ulcer protection of EEAP was statistically significant by ANOVA test $P<0.0001$, Positive control group does not play a significant role in ulcer index. $A$. procera showed a protection index of $74 \%$ with the dose of $200 \mathrm{mg} / \mathrm{kg}$ b.w compared to Negative control and Ranitidine as reference standard drug (Table 1). Ethanol is the most common ulcerogenic agent producing acute gastric hemorrhagic erosions when adminis- tered intragastrically to rats. Factors responsible for ethanol's gastric lesions were depletion of gastric mucus content and release of mucosal leukotrienes. Ethanol induces damage to the gastric mucosa via accumulated activated neutrophils that are a source of free radicals. Thus, Xanthine oxidase influences sufficient making of oxygen free radicals, which cause amplified LPO and cell membrane destruction (Dwivedi, et al.,2014). Histopathological evaluation in Positive control group showed normal mucosa, Negative control showed oedema, inflammation, degeneration, haemorrhage, in the ethanol-induced model. The treatment with $200 \mathrm{mg} / \mathrm{kg}$ b.w $A$. procera group indicated regeneration and prevention of haemorrhage and oedema formation whereas Ranitidine group showed almost normal appearance (Fig. 3). The histopathological observations showed that ethanol-induced damages to the mucosal epithelium had a nearly normal structure, fewer haemorrhage and necrosis because of prior treatment with $A$. procera ethanolic extract guards the gastric cells by subsiding the necrosis and haemorrhage against ethanol-induced injury as also stated by Alvarez-Suarez et al. ( 2011) for strawberry polyphenols that attenuate ethanolinduced gastric lesions in rats by activation of antioxidant enzymes and attenuation of MDA increase.

When administered orally with $A$. procera leaves extract $(200 \mathrm{mg} / \mathrm{kg})$, pylorus ligated animals displayed a decline in gastric acid production and change in its $\mathrm{pH}$, decrease of total acidity, and free acidity well fall in ulcer index while comparing it with the control group, Positive control group doesn't play a significant effect in these estimations. The rat stomach's glandular portion showed normal architecture in positive control, whereas Negative control showed redness, 5-6 red spots \& hemorrhagic streaks. Ranitidine group showed 1-2 red spots and EEAP group showed 2-3 red spots (Fig. 4). The ulcer index in Negative Control, Ranitidine (45mg/ $\mathrm{kg}$ oral) and EEAP (200mg/kg p.o) was $9.62 \pm 0.19$, $0.92 \pm 0.15,1.48 \pm 0.25$ respectively and was statistically significant $\mathrm{P}<0.0001$ (Table 2). A. procera had shown a protection index of $85 \%$ with the dose of 200 $\mathrm{mg} / \mathrm{kg}$ b.w compared to Negative control and Ranitidine as the reference standard (Fig. 4). The $\mathrm{p}^{\mathrm{H}}$ in Negative Control, Ranitidine and EEAP was $1.7 \pm 0.07,2.9 \pm 0.10$, $2.6 \pm 0.103$ respectively and was statistically significant $P<0.0001$. The gastric volume $(\mathrm{ml})$ in Negative Control, Ranitidine and EEAP was $3.12 \pm 0.0846$, $1.26 \pm 0.05426,1.44 \pm 0.1565$, respectively and was statistically significant $P<0.0001$. The free acidity (Meq//tr) in Negative Control, Ranitidine and EEAP was $21.66 \pm 1.944,9.6 \pm 0.4282,12.6 \pm 0.5578$ respectively and was statistically significant $P<0.0001$. The total acidity (Meq/ltr) in Negative Control, Ranitidine and EEAP was $82.0 \pm 2.176,38.4 \pm 1.430,51.2 \pm 1.167$ respectively and was statistically significant $P<0.0001$.

In the Pyloric-ligation model, treatment with $A$. procera 
Table 1. Ulcer inhibition in ethanol induced ulcers in rats.

\begin{tabular}{|c|c|c|c|}
\hline S. N. & Treatment & Ulcer index & $\%$ Ulcer Inhibition \\
\hline 1. & $\begin{array}{l}\text { Negative Control } \\
\text { (Group 2) }\end{array}$ & $9.25 \pm 0.15$ & - \\
\hline 2. & $\begin{array}{l}\text { Ranitidine ( } 45 \mathrm{mg} / \mathrm{kg} \mathrm{b.w}) \\
\text { (Group 3) }\end{array}$ & $1.11 \pm 0.18^{*}$ & $88 \%$ \\
\hline 3. & $\begin{array}{l}\text { EEAP (200mg/kg b.w) } \\
\text { (Group 4) }\end{array}$ & $1.85 \pm 0.15^{\star}$ & $74 \%$ \\
\hline
\end{tabular}

No. of rats in each group: 4; Values are expressed in terms of Mean \pm S.E.M, $(N=5){ }^{*} p<0.0001$ using one-way ANOVA followed by Dunnett's test

Table 2. Effect of EEAP on ulcer inhibition in pylorus ligation induced gastric ulceration in rats.

\begin{tabular}{llllllll}
\hline S. N. & Treatment & Ulcer index & $\begin{array}{l}\text { Protection } \\
\%\end{array}$ & $\begin{array}{l}\text { pHof gastric } \\
\text { juice }\end{array}$ & $\begin{array}{l}\text { Gastric } \\
\text { juice }(\mathrm{ml})\end{array}$ & $\begin{array}{l}\text { Free acidity } \\
\text { Meq/l }\end{array}$ & $\begin{array}{l}\text { Total acidity } \\
\text { Meq/l }\end{array}$ \\
\hline 1. & $\begin{array}{l}\text { Negative Control } \\
\text { (Group 2) }\end{array}$ & $9.62 \pm 0.19$ & - & $1.7 \pm 0.07$ & $3.12 \pm 0.0846$ & $21.66 \pm 1.944$ & $82.0 \pm 2.176$ \\
2. & $\begin{array}{l}\text { Ranitidine (45 mg/ } \\
\text { kg b.w) (Group 3) }\end{array}$ & $0.92 \pm 0.15^{*}$ & $90.4 \%$ & $2.9 \pm 0.106^{*}$ & $1.26 \pm 0.05426^{*}$ & $9.6 \pm 0.4282^{*}$ & $38.4 \pm 1.430^{*}$ \\
3. & $\begin{array}{l}\text { EEAP (200mg/kg } \\
\text { b.w) (Group 4) }\end{array}$ & $1.48 \pm 0.25^{*}$ & $85 \%$ & $2.6 \pm 0.1033^{*}$ & $1.44 \pm 0.1565^{*}$ & $12.6 \pm 0.5578^{*}$ & $51.2 \pm 1.167^{*}$ \\
\hline
\end{tabular}

No. of rats in each group: 4; Values are expressed in terms of Mean \pm S.E.M, ${ }^{*} p<0.0001$ using one-way ANOVA followed by Dunnett's test when compared with control.

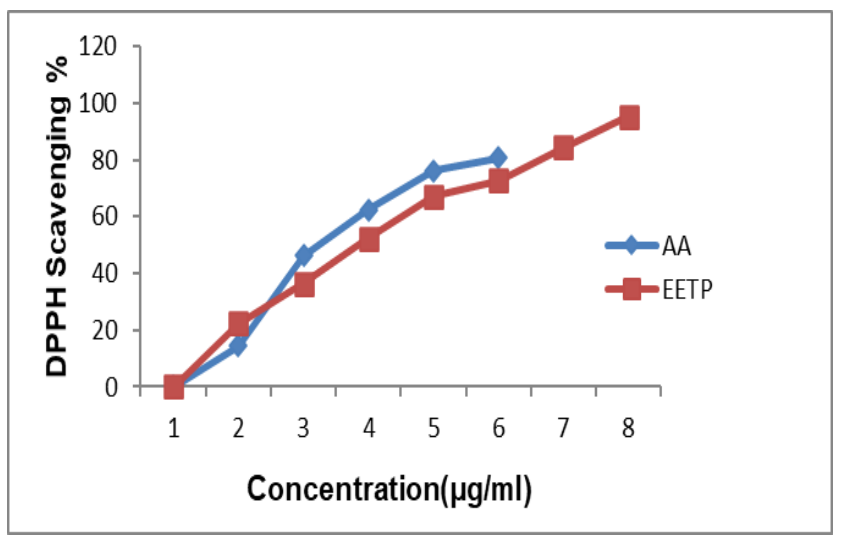

Fig. 1. DPPH scavenging activity of $A$. procera leaf extract $(E E A P)$ in-vitro.

showed cytoprotective mechanism on gastric mucosa and thus inhibited ulcers through considerably reducing the secretion of basal gastric acid, which is characteristic for beginning of ulcers. The various factors regulate gastric acid secretion such as histaminergic and gastrinergic neurotransmissions, including proton pump, anxiety effect, vagal activity, and irritant receptors (Waldum et al., 2013). The current data evidently established that anti-ulcerogenic activity of $A$. procera may be linked to its action of inhibiting the aggressive factors (acid and pepsin). These aggressive factors are a chief feature in the expansion of peptic ulcer. The consequences obtained from the current studies also showed that $A$. procera had anticholinergic and vagolytic activity as well as the inhibitory effect on irritant receptors. The mucous content of rats treated with EEAP was increased at a dose level compared to the Negative control group. The mucous content ( $\mu \mathrm{g}$ alcian blue/g wet glandular tissue) in Positive control, Nega- tive Control, Ranitidine and EEAP was $320.1 \pm 0.47$, $232.62 \pm 0.32,309.2 \pm 0.14,304.94 \pm 0.37$, respectively. $A$. procera increased the mucin content with the dose of $200 \mathrm{mg} / \mathrm{kg}$ b.w compared to the Negative control and Ranitidine as reference standard drug and was statistically significant $\mathrm{P}<0.0001$ (Table 3 ).

Consequently, A. procera may exhibit gastric mucosal protection by the potential mechanism of partially strengthening the mucosal barrier, reducing the acidity of gastric fluid, and increasing its $\mathrm{pH}$. Antiulcer drugs upsurge the mucus secretion consisting of mucin-type glycoproteins in the gastric mucosa. These glycoproteins could be determined by the quantity of alcian blue binding. The antioxidant enzyme catalase $\left(\mu \mathrm{ml} \mathrm{H}_{2} \mathrm{O}_{2} /\right.$ $\mathrm{min} / 100 \mathrm{mg}$ of tissue) in Positive control, Negative Control, Ranitidine and EEAP was 25.58 \pm 1.72 , $5.64 \pm 1.22, \quad 22.8 \pm 1.95,19.86 \pm 1.42$, respectively. $A$. procera increased the catalase with the dose of 200 $\mathrm{mg} / \mathrm{kg}$ b.w in comparison with the Negative control and Ranitidine as reference standard drug and was statistically significant $\mathrm{P}<0.0001$. The lipid peroxidation (nmol of MDA/mg protein) in Positive control, Negative Control, Ranitidine and EEAP was 24.82 \pm 0.66 , $39.84 \pm 0.52,26.42 \pm 0.06,27.02 \pm 0.27$, respectively. $A$. procera decreased the lipid peroxidation (LPO) with the dose of $200 \mathrm{mg} / \mathrm{kg}$ b.w in comparison with the Negative control and Ranitidine at $45 \mathrm{mg} / \mathrm{kg}$ as reference standard drug and was statistically significant $P<0.0001$ (Table 3).

Reactive oxygen species (ROS) are generated through numerous normal metabolic processes and are needed for the organism's malfunctioning. Various antioxidant enzymes like SOD and CAT reduces their accumulation. Any imbalance in these enzymes' activity normally 
Table 3. Effect of EEAP on catalase activity, lipid peroxidation and mucous content.

\begin{tabular}{llll}
\hline Treatment & $\begin{array}{c}\text { CAT }\left(\mu \mathrm{ml} \mathrm{H}_{2} \mathrm{O}_{2} / \mathrm{min} / 100\right. \\
\text { mg of tissue) }\end{array}$ & $\begin{array}{l}\text { LPO (nmole of } \\
\text { MDA/mg protein) }\end{array}$ & $\begin{array}{l}\text { Mucous content } \\
(\mu \text { g alcian blue/g wet } \\
\text { glandular tissue) }\end{array}$ \\
\hline $\begin{array}{l}\text { Positive control } \\
\text { (Group 1) }\end{array}$ & $25.58 \pm 1.72$ & $24.82 \pm 0.66$ & $320.1 \pm 0.47$ \\
$\begin{array}{l}\text { Negative control } \\
\text { (Group 2) }\end{array}$ & $5.64 \pm 1.22$ & $39.84 \pm 0.52$ & $232.62 \pm 0.32$ \\
$\begin{array}{l}\text { Ranitidine (45 mg/kg b.w) } \\
\text { (Group 3) }\end{array}$ & $22.8 \pm 1.95^{*}$ & $26.42 \pm 0.06^{*}$ & $309.2 \pm 0.14^{*}$ \\
$\begin{array}{l}\text { EEAP (200mg/kg b.w) } \\
\text { (Group4) }\end{array}$ & $19.86 \pm 1.42^{*}$ & $27.02 \pm 0.27^{*}$ & $304.94 \pm 0.37^{*}$ \\
\hline
\end{tabular}

No. of rats in each group: 4; Values are expressed in terms of Mean \pm S.E.M, ${ }^{*} p<0.0001 \mathrm{v} / \mathrm{s}$ ulcerated control group using one-way ANOVA followed by Dunnett's test

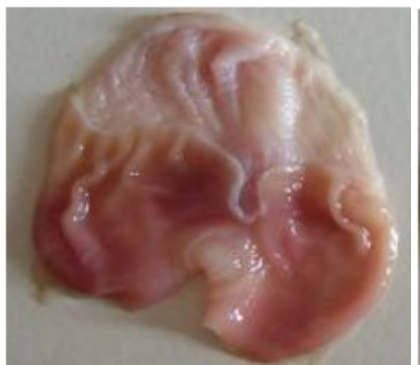

a) Positive control

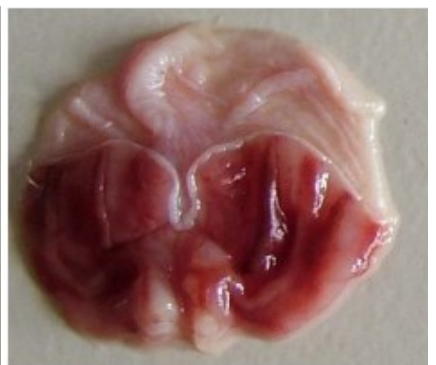

b) Negative Control

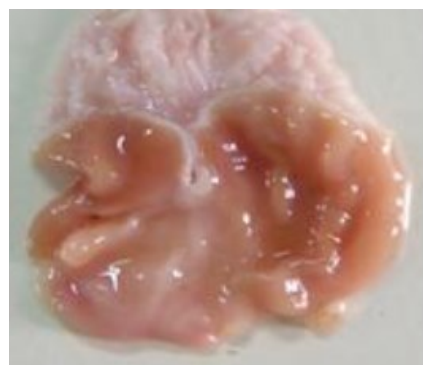

c) Standard

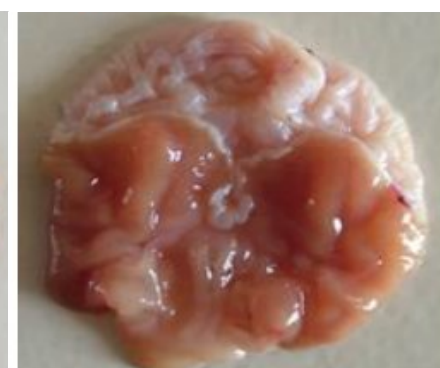

d) EEAP

Fig. 2. Rat stomach glandular portion (a) Positive control showing normal architecture (b) Negative control (treated with $1 \mathrm{~m} / \mathrm{kg}$ b.w Ethanol) showing redness, 8-10 red spots \& Hemorrhagic streaks. (c) Standard (treated with Ranitidine $45 \mathrm{mg} /$ kg b.w) showing 1-2 red spots (d) Test (treated with EEAP 200mg/kg b.w EEAP) showing 1-2 red spots.

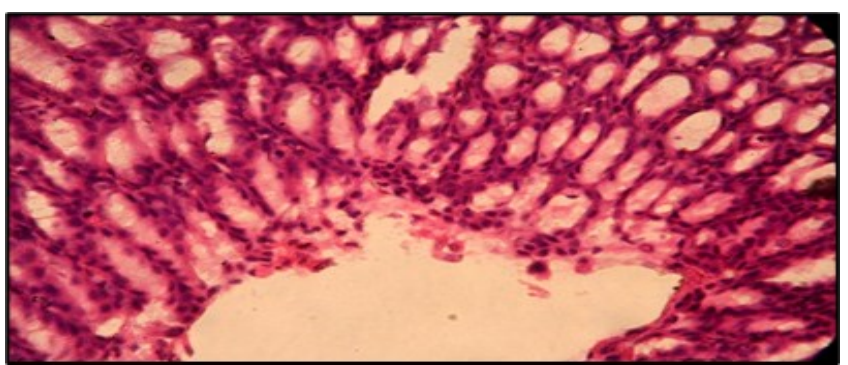

a) Positive control

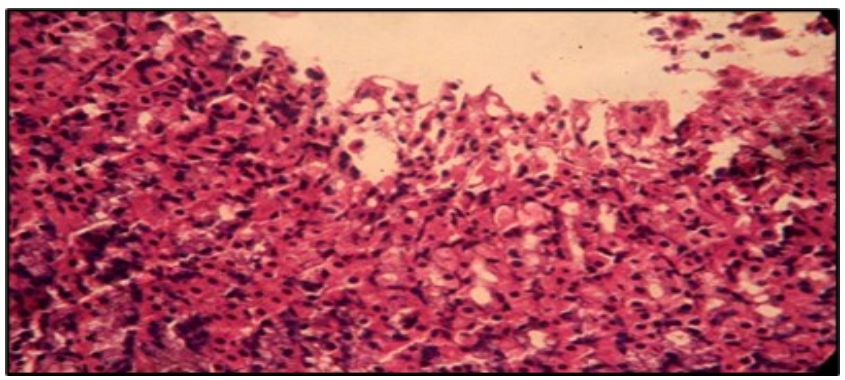

c) Standard

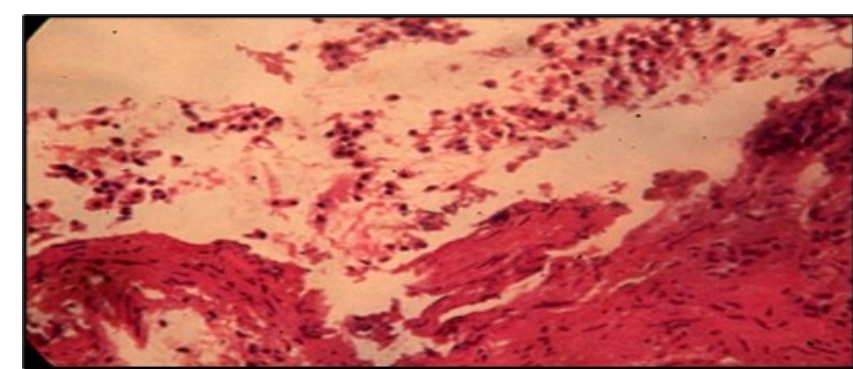

b) Negative Control

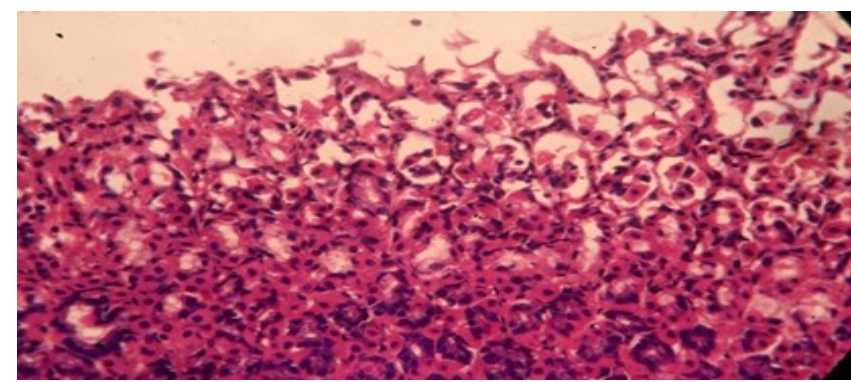

d) EEAP

Fig. 3. Histopathological evaluation of Ethanol Induced Gastric Ulcers (a)Positive control showing normal mucosa (b) Negative control showing inflammation \& mucosal ulceration control, (c) Standard drug Ranitidine (45mg/kg b.w) showing no significance change in histopathology almost normal appearance, (d) Test group EEAP (200mg/kg b.w) showing no significance change in histopathology almost normal appearance.

leads to faulty disposal of free radicals and their accumulation. These ROS are responsible for the oxidation of tissues leading to lipid peroxidation and tissue damage. The antiulcer effect was also reinforced by increasing catalase activity and decreasing LPO. The antisecretory and antiulcerogenic activity of $A$. procera observed in the present study was done on the leaves collected from Indo-Gangetic region of India, which showed improvised quality of phytoconstituents due to changed chemotaxonomy which suggests the better 


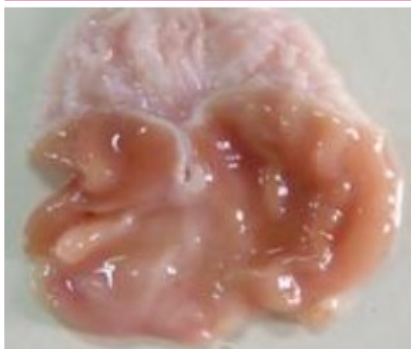

a) Positive control

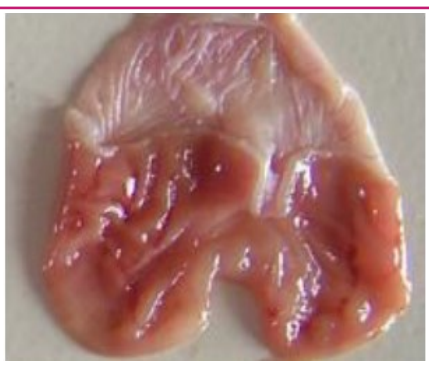

b) Negative Control

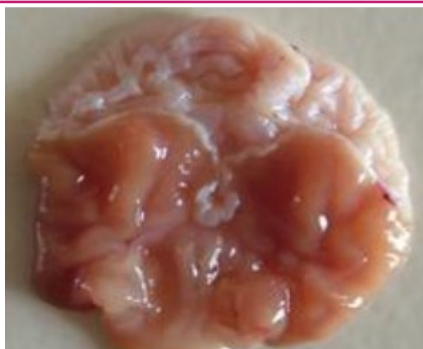

c) Standard

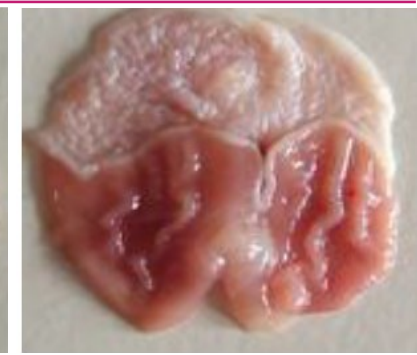

d) EEAP

Fig. 4. Rat stomach glandular portion (a) Positive control showing normal architecture (b) Negative Control (Ulcer induced by pylorus ligation) showing redness, 5-6 red spots \& hemorrhagic streaks (c) Standard (treated with Ranitidine $45 \mathrm{mg} / \mathrm{kg} \mathrm{b.w}$ and showing protected mucosal layer with 1-2 red spots only (d) Test (treated with EEAP 200mg/kg b.w and showing protected mucosal layer with 1-2 red spots only

antiulcer activity, cytoprotective activity, in vitro and in vivo antioxidant activities (Ambika and Jegadeesan, 2017). The mechanism behind its gastroprotective effect in wistar rats may be assigned to reduced vascular penetrability, decreased generation of free radicals and LPO in addition to strengthening of mucosal barrier. Besides, the occurrence of phytoconstituents in the plants, such as flavonoids and tannins, might be responsible for this activity.

\section{Conclusion}

The present study concluded that the leaves of $A$. procera possessed antiulcer, antioxidant, antisecretory and cytoprotective property and possibly acted via various mechanisms including free radical scavenging action. The leaves extract significantly showed ulcer healing potential. The leaves extract was found to contain a noticeable amount of total phenols and flavonoids, which might have played a major role in controlling the oxidation and exhibited cytoprotection. The current activity confirmed the antiulcer protective ability of $A$. procera being effective in managing gastric ulcers; therefore, further study is needed to isolate and identify the active principles present in the extract responsible for the antiulcer activity.

\section{ACKNOWLEDGEMENTS}

The authors would like to acknowledge Amity University, Lucknow, and Motherhood University, Roorkee, to issue laboratory benefits and motivate our work.

\section{Conflict of interest}

The authors declare that they have no conflict of interest.

\section{REFERENCES}

1. Aebi, H. (1984). Catalase in vitro. In Methods in enzymology, Academic Press, 105, pp 121-126. https:// doi.org/10.1016/S0076-6879(84)05016-3
2. Akhtar, M.S., Akhtar, A.H., and Khan, M.A. (1992). Antiulcerogenic effects of Ocimum basilicum extracts, volatile oils and flavonoid glycosides in albino rats. Int. J. Pharmacogn,30(2), 97-104. https://doi.org/10.3109/1388020920 9053966

3. Alvarez-Suarez, J.M., Dekanski, D., Ristić, S., Radonjić, N.V., Petronijević, N.D., Giampieri, F., Astolfi, P., Gonzalez-Paramas, A.M., Santos-Buelga, C., Tulipani, S., and Quiles, J.L. (2011). Strawberry polyphenols attenuate ethanol-induced gastric lesions in rats by activation of antioxidant enzymes and attenuation of MDA increase. PLoS One, 6(10): e25878. https://dx.doi.org/10.1371\% 2Fjournal.pone.0025878

4. Ambika, K., and Jegadeesan, M. (2017). Antiulcer activity of $A$. procera leaves in different growth phases. Int $J$ Innov Res Sci Eng Technol, 6(9), 19495-19499. DOI:10.15680/ IJIRSET.2017.0609149

5. Ariypshi, I. (1986). Recurrence during maintenance therapy with histamine $\mathrm{H}_{2}$ receptors antagonists in cases of gastric ulcers. Nikon Univ J Med, 28, 69-74.

6. Azamthulla, M., Balasubramanian, R., and Kavimani. (2015). A review on medicinal plants exhibiting antifertility activity. WJPPS, 4(3), 243- 72.

7. Brzozowski, T., Konturek, P.C., Konturek, S.J., Kwiecien, S., Pajdo, R., Brzozowska, I., and Hahn, E.G. (1998). Involvement of endogenous cholecystokinin and somatostatin in gastroprotection induced by intraduodenal fat. $J$. Clin. Gastroenterol,27(1), S125-137. https:// doi.org/10.1016/s0167-0115(99)00029-4

8. Buege, J.A., and Aust, S.D. (1978). Microsomal lipid peroxidation Method. Enzymol, 52(1):302-310. https:// doi.org/10.1016/S0076-6879(78)52032-6

9. Dwivedi, V., Chander, B.S., and Yadav, N.H. (2014). Evaluation of antiulcer activity of Clitorea ternatea Leaves (Linn) extract in Wistar rats. Indian J. Biotech. Pharm. Res, 3,1225-29.

10. Kedare, S.B., and Singh, R.P. (2011). Genesis and development of DPPH method of antioxidant assay. Int $J$ Food Sci Tech, 48(4), 412-22. https://dx.doi.org/10.1007\% 2 Fs13197-011-0251-1

11. Khandelwal, K.R. (2002). Practical Pharmacognosy, Technique and Experiments, $9^{\text {th }}$ ed. Nirali Prakashan, 23.1023.11, pp 25.1-25.6.

12. Kokate, C.K., Purohit, A.P., and Gokhle, S.B. (2015). Pharmacognosy, $51^{\text {st }}$ ed. Nirali Prakashan, Pune, pp7.167.18 .

13. Kokila, K.A., Priyadharshini, S.D., Sujatha, V. (2013). Phy- 
topharmacological properties of Albizia species: A Review. International Journal of Pharmacy and Pharmaceutical Sciences, 5:70-73.

14. Khatoon, M.M., Khatun, M.H., Islam, M.E., Parvin, M.S. (2014). Analgesic, antibacterial and central nervous system depressant activities of Albizia procera leaves. Asian Pacific Journal of Tropical Biomedicine, 4:279-84.

15. Kumar, S.K., Mruthunjaya, K., and Mythreyi, R. (2013). Antiulcer activity of ethanol extract of the stem bark of Carea arborea Roxb. Int. Curr. Pharm. J, 2(3):78 http:// dx.doi.org/10.3329/icpj.v2i3.13633

16. Misra, V., Yadav, G., Uddin, S.M., and Srivastava, V. (2012). Determination of antiulcer activity of Plumeria Rubra leaves extract. Int. Res. J. Pharm, 3(9),194-197.

17. Pekal, A., and Pyrzynska, K. (2014). Evaluation of aluminium complexation reaction for flavonoid content assay. Food Analytical Methods, 7(9),1776-82. https:// doi.org/10.1007/s12161-014-9814-x

18. Pillai, N.R., Suganthan, D., Seshari, C., and Santhakumari G. (1978). Antigastric ulcer activity of nimbidin. Indian $J$ Med Res, 68,169-175.

19. Prabha, T., Babu, M.D., Priyambada, S., Agrawal, V.K. and Goel, R.K. (2003). Evaluation of Pongamia pinnata root extract on gastric ulcers and mucosal offensive and defensive factors in rats. Indian Journal of Experimental Biology, 41(03), 304-310.

20. Ruchi, M., \& Rekha, V. (2017). Determination of total flavonoid and Phenol content in Mimusops elengi Linn. International Journal of Pharmaceutical sciences \& Research,8 (12), 5282-5285. DOI: 10.13040/IJPSR.0975-8232.8 (12).5282-85

21. Saranya, P., Geetha, A., Selvamathy, S.N. (2011) A biochemical study on the gastroprotective effect of andrographolide in rats induced with gastric ulcer. Indian journal of pharmaceutical sciences. 73(5), 550.

22. Sivakrishnan, S., \& Swamivelmanickam (2019). A comprehensive review on Albizzia procera (Roxb.) Benth. An update. Indian Journal of Pharmaceutical Science and Research,10(9), 4129-4144.

23. Srivastava, V., Viswanathswamy, A.H.M., and Mohan, G. (2010). Determination of the antiulcer properties of Sodium cromoglycate in albino rats. Indian J. Pharmacol, 42,185-188. https://DOI: 10.4103/0253-7613.66844

24. Waldum, H.L., Hauso, O and Fossmark R. (2013). The regulation of gastric acid secretion- clinical perspectives. Acta Physiologica, 210(2), 239-256. 